\title{
KYLIE MATHESON: CERAMIC ARTIST
}

\section{Pam McKinlay}

A butterfly alights delicately on a fox's nose. Is it an unintended passing encounter or a greeting of two unexpected friends: Butterfly and Fox? We bring our own dialogue to this silent moment of innocence and trust. Kylie Matheson's hand-built sculptures evoke an emotional response in the viewer, of curiosity and wonder. Drawing inspiration from animals and their behaviour, Matheson focuses on the secret relationships between her characters and draws in the viewer, to create their own narratives between the ceramic duos and scenes she creates between them.

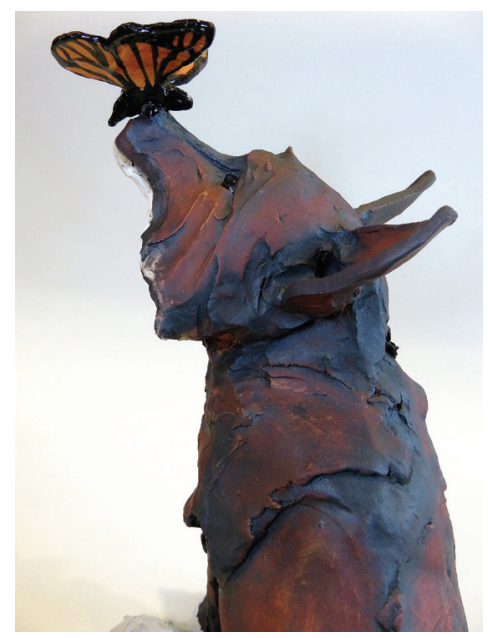

Figure I. Kylie Matheson, Fox and Butterfly, 2019 , ceramic, hand-built paper clay, oxide wash and engobe, $280 \times 240 \times 250 \mathrm{~mm}$.

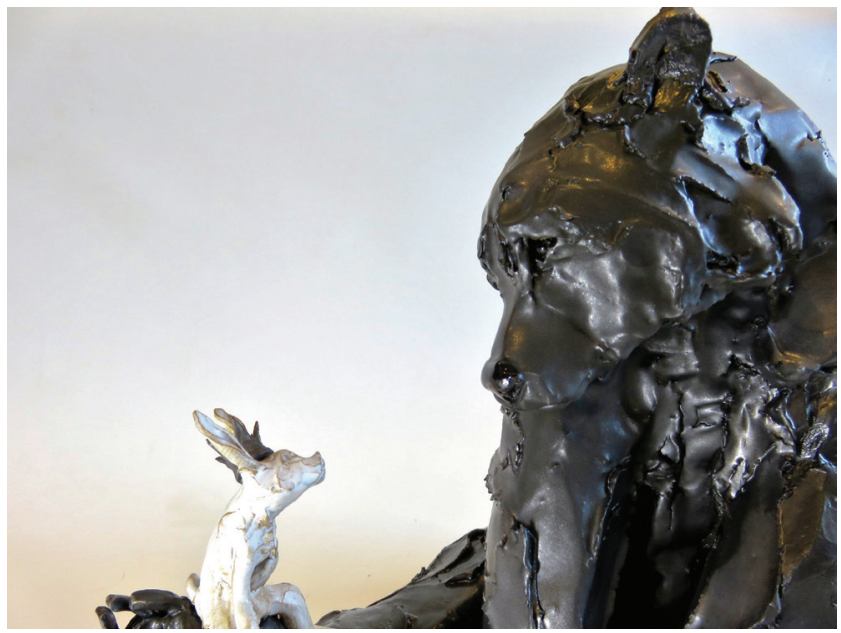

Figure 2. Kylie Matheson, Grizzly and Queen Rabbit, 2019 , ceramic, hand-built paper clay, satin glaze, $280 \times 250 \times 340 \mathrm{~mm}$.

\section{ODD COUPLES - SECRET WORLDS}

Grizzly and Queen Rabbit are another unlikely couple. Grizzly and Queen Rabbit's conversations are a series of vignettes which chronicle the relationship of two friends. Grizzly is strong and gentle, an older and wiser character. Rabbit is an independent soul, feisty and stubborn, making her own way in the world, but she values her friend Grizzly and the reciprocity of their friendship. The protection offered by Grizzly is metaphorically asserted by Grizzly's size and bulk and juxtaposed against the lightness of touch in the creation of Queen Rabbit. The pair are modelled again and again mid conversation. What are they saying? Listen closely. Each piece adds to the ongoing story of Grizzly and Queen Rabbit in their unfolding exchanges. Look closely. 


\section{OTHER-WORLD ADVENTURERS}

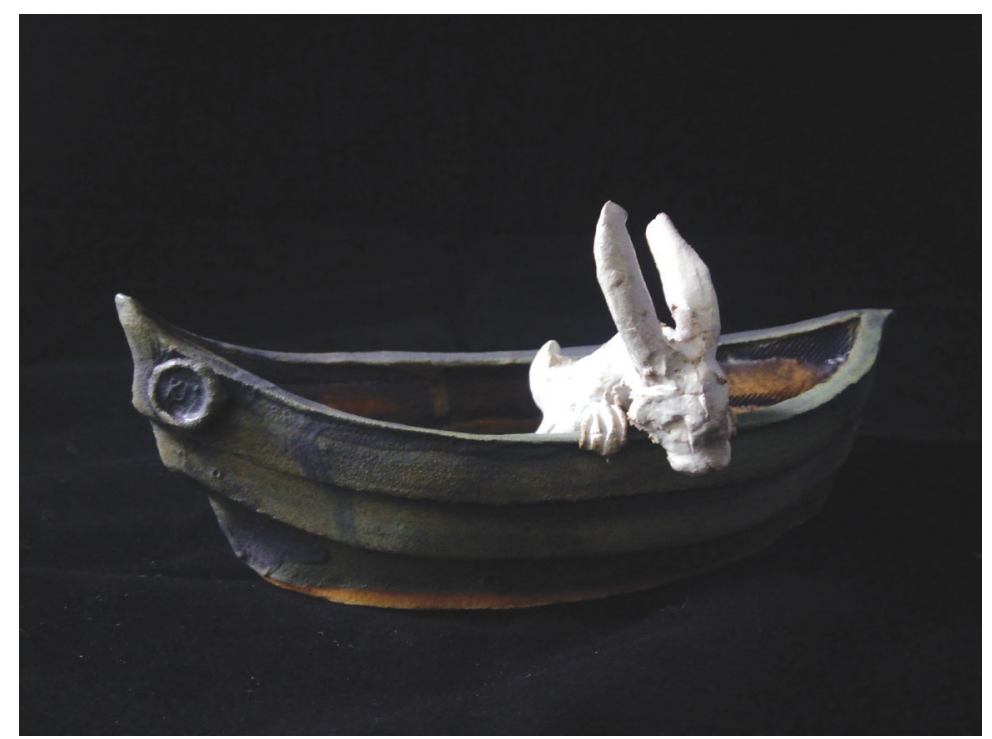

Figure 3. Kylie Matheson, The Drifters, 2019, ceramic, hand-built paper clay, oxide wash and engobe, $170 \mathrm{~mm} \times 90 \mathrm{~mm}$

Rabbit goes on long adventures. There's no owl and the pussycat aboard her green vessel, just Rabbit setting off alone into the unknown in her small wooden skiff. Adrift on a windowsill, mantle-piece or table. Sometimes peering over the side, or at the bow looking for land ho, sometimes lying back with legs crossed in contemplation of the clouds in the sky. Always on the way, never arriving.

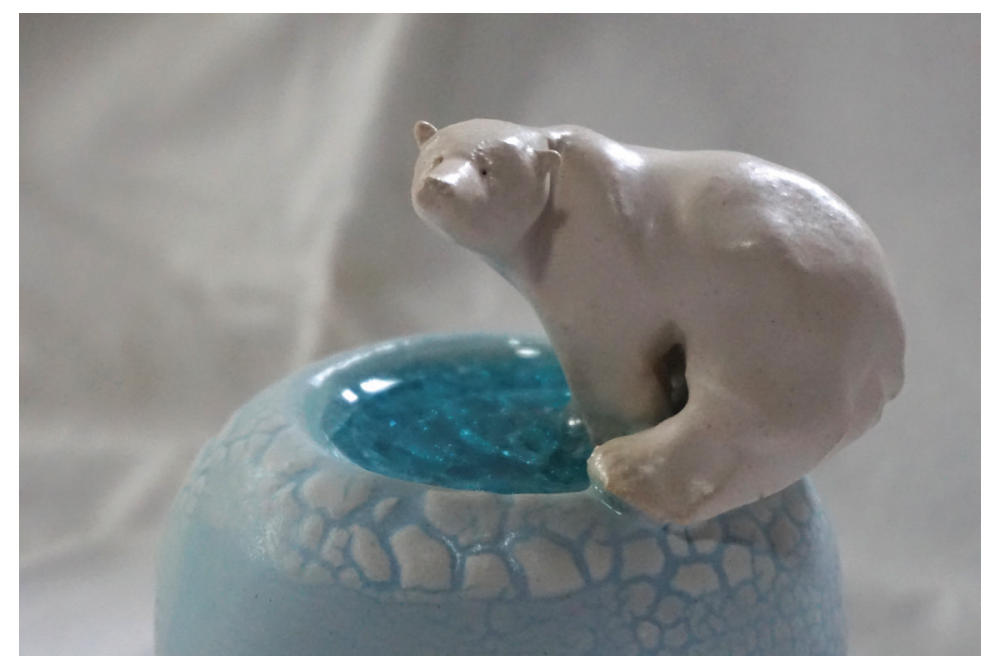

Figure 4. Kylie Matheson, Polar Bear, 2019, ceramic, hand-built paper clay, oxide wash and engobe, $100 \mathrm{~mm} \times 100 \mathrm{~mm} \times 110 \mathrm{~mm}$. 
White Bear puts his paw in a glassy puddle of glacial blue melt water. The gesture is highly symbolic at a time of heightened climate change awareness. Is she standing at the edge of the precipitous ice sheet or on the edge of a shrinking iceberg? Either way her fate is the same, sink or swim and into the water she must go. She looks up before she takes the plunge. One last look to see if there are other options on the near horizon. One last look, our eyes locking, imploring us to act. In the latest of Matheson's creations, the animals are not always the masters and mistresses of their own fate. They break the fourth wall, and worlds become one.

Matheson engages the viewer in a world of figurines in conversation, in action, at rest and on their way. On their way to where you might ask? Don't ask me. We must cross the boundary and step into this other-world, arrested in the moment with the animals we encounter in front of us. At once playful and thoughtful, Kylie's sculptures reveal a raw vulnerability in the relationships between the creatures, capturing a delicate balance between the big and the small, the tough and the fragile. A world of trust and reciprocity between all creatures.

Kylie Matheson is a practising Dunedin ceramic artist. Kylie has won numerous awards including the Cleveland National Art Award, been guest artist for Ceramics NZ and received a merit award in the 2019 Portgage Ceramic awards.

Pam McKinlay (-ORCID No: https://orcid.org/0000-0002-1731-6437) works part-time for the Dunedin School of Art and Research Office at Otago Polytechnic. She has an academic background in applied science and history of art and is an artist who is a maker predominantly in weaving, ceramics and photography. 